\title{
INOVASI METODE LIFTING BENTANG UTAMA JEMBATAN SEI WAMPU DI SUMATERA UTARA
}

\author{
Andrew Nugraha Standyarto \\ Jabatan Fungsional Teknik Jalan dan Jembatan Ahli Pertama \\ ${ }^{1}$ Direktorat Pembangunan Jembatan Direktorat Jenderal Bina Marga Kementerian PUPR, \\ email:andrew.standyarto@pu.go.id
}

\begin{abstract}
Abstrak:Jembatan merupakan bagian integral dari Infrastruktur jalan yang dibangun untuk menunjang konektivitas dan mobilitas masyarakat Indonesia dalam kegiatan ekonomi. Untuk menjamin konstruksi jembatan terbangun dengan aman dan sesuai desain, diperlukan pemilihan metode konstruksi yang tepat, terutama untuk pelengkung baja sepanjang $140 \mathrm{~m}$ yang merupakan bentang utama Jembatan Sei Wampu. Jembatan Sei Wampu merupakan jembatan yang terletak pada ruas jalan nasional dan menghubungkan daerah Stabat dengan Tanjung Pura di Provinsi Sumatera Utara. Paket pembangunan Jembatan Sei Wampu mengalami putus kontrak pada tahun 2019 dimana sistem lantai bentang utama jembatan berupa stringer dan cross girder telah terpasang di tengah sungai menggunakan sistem shoring. Maka dari itu, menindaklanjuti rencana tender lanjutan, dibutuhkan inovasi metode lifting elemen pelengkung dan hanger untuk menyelesaikan pekerjaan pemasangan bentang utama. Dengan menggunakan pendekatan studi literatur dan tinjauan lapangan, metode lifting ditentukan menggunakan tower backstay dan lifting segmen menggunakan heavy crane pada platform beton sementara di kedua sisi abutmen. Dari hasil analisis pengecekan radius dan load chart crane untuk segmen terberat Top Chord (TC), heavy crane 450 ton dipilih untuk melakukan lifting 6 segmen di arah Stabat dan heavy crane 450 ton + superlift 180 ton untuk lifting 9 segmen arah Tj. Pura dengan pondasi platform tiang pancang baja ø $60 \mathrm{~cm}$ berjumlah 9 . Dengan telah ditentukannya metode lifting, tender paket pembangunan Jembatan Sei Wampu pun dapat dilakukan.
\end{abstract}

Kata-kata kunci: jembatan pelengkung, lifting, heavy crane, pancang baja.

Abstract: The bridge is an integral part of the road infrastructure that is built to support the connectivity and mobility of the Indonesian people in economic activities. To ensure that the bridge construction is built safely and according to the design, it is necessary to choose the right construction method, especially for the $140 \mathrm{~m}$ long steel arch which is the main span of the Sei Wampu Bridge. The Sei Wampu Bridge is a bridge located on the national road and connects the Stabat area with Tanjung Pura in North Sumatra Province. The Sei Wampu Bridge construction package ended the contract in 2019 where the main span floor system of the bridge in the form of stringers and cross girders was installed in the middle of the river using a shoring system. Therefore, following up on the follow-up tender plan, innovation in the lifting method of arch elements and hangers is needed to complete the main span installation work. Using a literature study and field review approach, the lifting method was determined using a tower backstay and segment lifting using a heavy crane on a temporary concrete platform on both sides of the abutment. From the results of the analysis of checking the radius and load chart of the crane for the heaviest segment of the Top Chord (TC), a heavy crane of 450 tons was chosen to carry out lifting 6 segments in the Stabat direction and a heavy crane 450 tons +180 tons superlift for lifting 9 segments in the Tj direction. There are 9 temples with steel pile platform foundations of $60 \mathrm{~cm}$. With the lifting method determined, a tender for the construction package of the Sei Wampu Bridge can also be carried out.

Keywords: arch bridge, lifting, heavy crane, steel pile.

\section{PENDAHULUAN}

Jembatan Sei Wampu merupakan jembatan duplikasi jembatan eksisting tipe Rangka Baja Australia (RBA) yang berada pada Kota Stabat, Provinsi Sumatera Utara dan menghubungkan daerah Stabat dengan Tanjung Pura, Kota Medan dengan Aceh. Jembatan ini merupakan jembatan dengan bentang utama $140 \mathrm{~m}$ dengan tipe pelengkung box baja dan bentang pendekat pile slab seperti terlihat pada Gambar 1.1 berikut: 


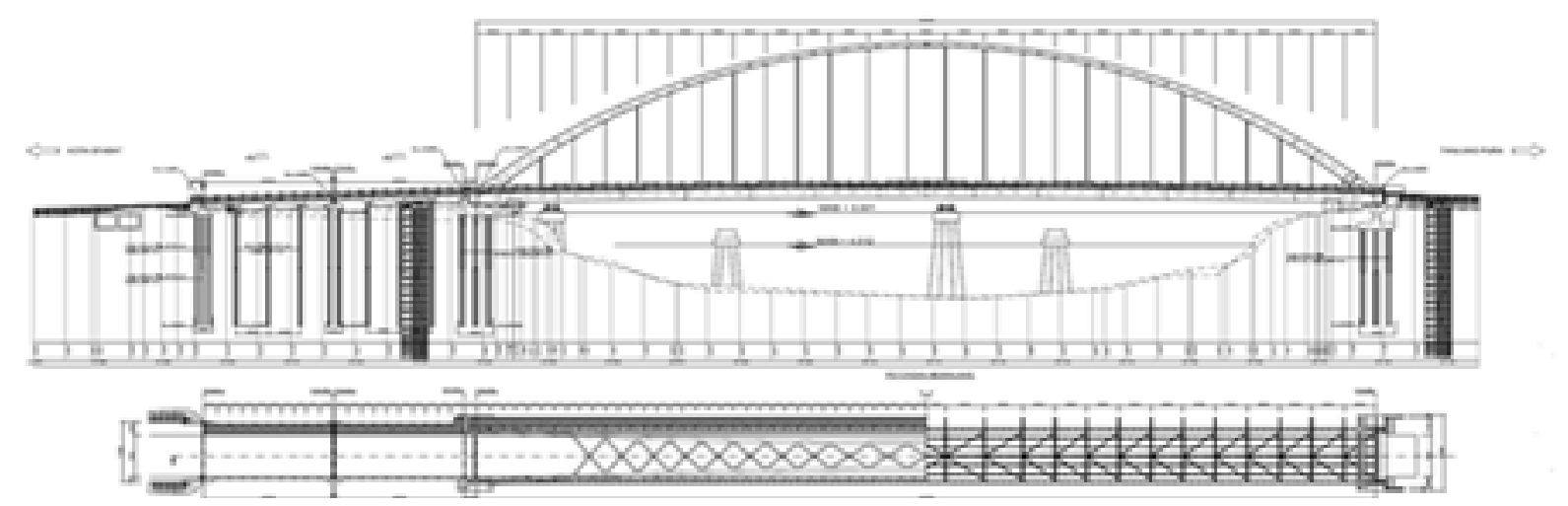

Gambar 1.1 Long Section dan Plan View Jembatan Sei Wampu

Paket Pembangunan Jembatan Sei Wampu, mengalami putus kontrak pada tahun 2019 sehingga kondisi elemen jembatan perlu dilakukan pengecekan kembali. Pada kontrak sebelumnya, sistem lantai bentang utama telah terpasang di tengah sungai sehingga penggunaan metode konvensional seperti shoring akan sulit dilakukan. Untuk menyelesaikan metode bentang utama, diperlukan metode inovatif seperti horizontal swing, vertical swing atau tower backstay dengan heavy lifting. Menilai dari kemudahan dan biaya konstruksi, metode lifting pun direncanakan dari bantaran sungai menggunakan heavy crane yang dilengkapi dengan superlift untuk memastikan radius dan load chart crane terpenuhi untuk setiap lifting segmennya. Pada penelitian ini, metode lifting meliputi pemilihan alat angkat beserta struktur perkuatan sementara sesuai kondisi lapangan yang diperlukan akan dibahas.

\subsection{Jembatan Pelengkung/Busur (Arch)}

Jembatan pelengkung merupakan jenis bangunan atas struktur jembatan yang memanfaatkan prinsip mekanika teknik pelengkung 3 sendi. Tipe perletakan merupakan statis tertentu sendi dan rol pada tiap sisi dengan penahan gaya horizontal yang kuat berupa abutmen tiap sisi (Manual Pemeliharaan Jembatan Pelengkung Baja, 2011). Pemilihan bentang utama pelengkung lebih dari $60 \mathrm{~m}$ yang termasuk jembatan khusus terutama karena faktor lebar sungai tidak memungkinkan adanya pilar yang mengurangi penampang basah sungai, faktor estetika sebagai ikon daerah, faktor waktu dimana elemen baja dapat dipabrikasi bersamaan dengan pengerjaan bangunan bawah di lapangan \& faktor mutu karena elemen yang diproduksi di pabrik akan lebih terjamin kualitas pengerjaannya (executive summary). Tergantung lokasi lantainya, jembatan pelengkung dibagi menjadi 3 jenis yaitu dek, menerus (through) dan mengikat (tied). Jembatan pelengkung mengikat (tied) terdiri atas elemen pelengkung, hanger dan stiffening girder atau sistem lantai (lantai beton bertulang, balok transversal/cross girder dan longitudinal/stringer) sebagai berikut pada Gambar 1.2:

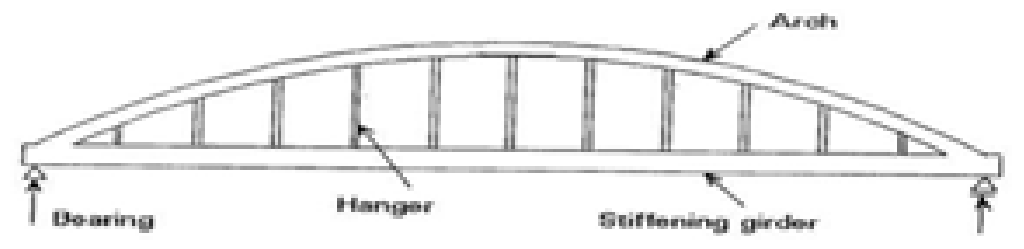

Gambar 1.2 Jembatan Pelengkung Mengikat/Tied (Manual Pemeliharaan Jembatan Pelengkung Baja, 2011) 
Penggunaan sistem hanger akan berpengaruh saat fase pemeliharaan (preservasi) dimana arus lalu lintas akan tetap dapat operasional, minim terganggu dan tidak diperlukan alat berat saat kegiatan preservasi struktur. Jembatan pelengkung dapat terbuat dari material beton maupun baja, pemilihan material didasarkan pada bentang maksimum jembatan dimana beton mencapai $420 \mathrm{~m}$ dan baja hingga $550 \mathrm{~m}$ (Prasmoro, R., et al, 2017) serta kecepatan pemasangan dimana elemen baja dapat diproduksi terlebih dahulu dengan segmentasi yang lebih kecil.

Sistemstrukturpelengkungmemungkinkanalirangaya(bebanmati\&hiduplalulintas)yangditerima sistem lantai beton bertulang \& steel deck yang bekerja secara komposit karena shear connector diteruskan oleh cross girder yang diperkaku stringer ke pin hanger bawah, kabel hanger, pin hanger atas, elemen box pelengkung, lalu ke bangunan bawah pier, pile cap dan diteruskan oleh pondasi ke tanah sebagai gaya normal tekan tanpa lenturan dengan diagram sebagai berikut pada Gambar 1.3:

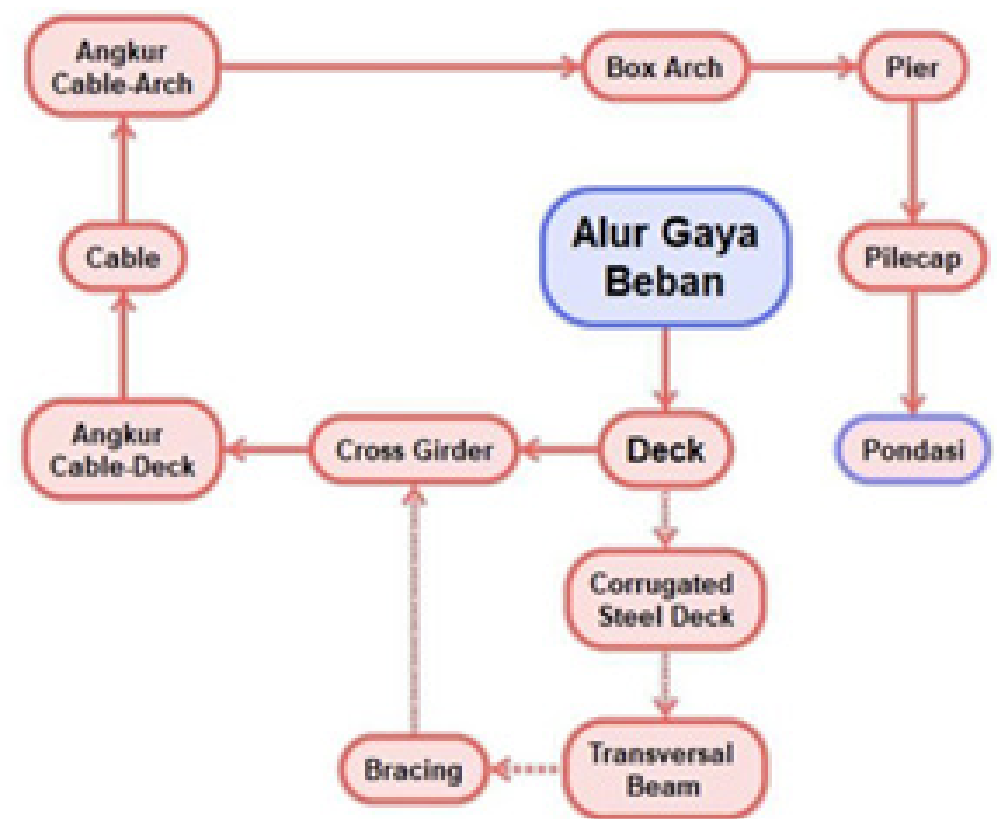

Gambar 1.3 Diagram Aliran Gaya Struktur Pelengkung (Executive Summary Jembatan Kalikuto Proyek Jalan Tol Batang-Semarang Seksi 2, 2018)

Jembatan pelengkung yang kompleks memungkinkan beberapa metode pemasangan untuk diterapkan seperti penggunaan shoring dan tower backstay pada full cantilever method dengan feeding segmen menggunakan alat angkat berupa crane. Pemilihan metode pemasangan didasarkan pada biaya yang tersedia, waktu, kompleksitas metode dan lokasi pekerjaan.

\subsection{Alat Angkat}

Dalam pelaksanaan pekerjaan lifting diperlukan alat berat berupa alat angkat yang dapat dipastikan mampu dan aman mengangkat tiap elemen jembatan. Alat angkat perlu memiliki mekanisme gerakan seperti mengangkat muatan (lifting) menggeser (trolleying), menahannya tetap di atas bila diperlukan dan membawa muatan ke tempat yang ditentukan (slewing dan travelling) (Ismerianto, et. al). Sesuai Permen PUPR No. 21/2019 tentang Pedoman Sistem Manajemen Keselamatan Konstruksi, penggunaan alat angkat merupakan pekerjaan risiko tinggi sehingga peng- 
gunaan crane harus sangat memperhatikan kapasitas angkat, radius \& load chart crane itu sendiri. SF yang digunakan adalah 2 sesuai Komite Keselamatan Konstruksi (K2K) dan Permenaker No.8/2020. Dibanding metode launcher misalnya, metode crane terbukti lebih cepat dan efisien dalam pekerjaan erection (Izza, R. K., et al, 2019). Terdapat 2 jenis crane yaitu crawler dengan kapasitas lebih besar dan mobile dengan keunggulan pada mobilitasnya. Untuk meningkatkan kapasitas lifting, penambahan counterweight dalam bentuk superlift dapat digunakan pada crawler crane. Kapasitas Safe Working Load (SWL) crane ditentukan pada load chart setiap tipe crane tergantung pada beban yang diangkat, sudut boom dan radius crane dengan beban yang diangkat.

\subsection{Pondasi Platform}

Bidang tempat crane berpijak juga harus diperhatikan karena momen yang besar saat crane melakukan swing dapat menyebabkan kegagalan guling. Penempatan alat berat yang tepat pada lokasi kegiatan dapat menjamin kelancaran proyek. Proses perencanaan awal adalah dengan cara menganalisa kondisi lokasi proyek, diantaranya dengan cara mengatur jalur mobilisasi alat tersebut terhadap perencanaan tata letak atau penempatan baik itu penimbunan material, gudang, kantor dan lain-lain. Karena berat crane, untuk memastikan crane berada pada dudukan yang stabil, dibutuhkan pondasi pada platform crane. Tiang pancang baja dipilih karena tergolong ekonmis (Nurdin, F., et al, 2016) untuk struktur sementara. Untuk tanah dengan lapisan keras yang dalam, diperlukan pondasi dalam seperti tiang yang memanfaatkan daya dukung ultimit $(\mathrm{Qu})$ sebagai penjumlahan tahanan ujung $(\mathrm{Qb})$ dan friksi atau geser sisi tiang (Qs). Rumus daya dukung pondasi tiang Meyerhof (1976) berdasar data Standard Penetration Test (SPT) dan klasifikasi tanah tiap lapisan hasil sampel bor:

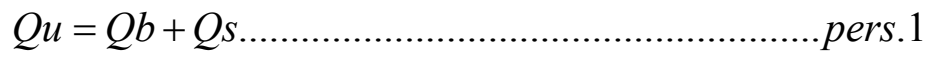

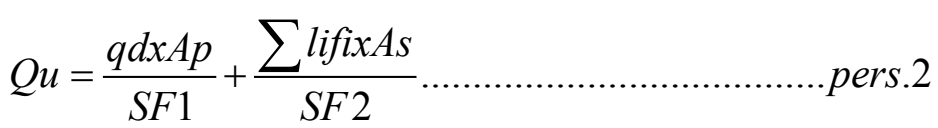

Dimana :

qd : $20 \mathrm{~N}$, untuk silt/clay $\left(\right.$ ton $\left./ \mathrm{m}^{2}\right)$

$30 \mathrm{~N}$, untuk silt/clay dalam kondisi cemented (ton $/ \mathrm{m}^{2}$ )

$40 \mathrm{~N}$, untuk sand (ton $\left./ \mathrm{m}^{2}\right)$

$\mathrm{N} \quad$ : Nilai N-SPT

D : Diameter tiang (cm)

Ap : Luas penampang tiang $\left(\mathrm{cm}^{2}\right)=\pi \mathrm{D}^{2} / 4$

As : Keliling penampang tiang $\left(\mathrm{cm}^{2}\right)=\pi \mathrm{D}$

li : Panjang segmen tiang yang ditinjau (m)

fi : Gaya geser pada selimut tiang (ton $\left./ \mathrm{m}^{2}\right)$

$\mathrm{N}$ maksimum 12 ton $/ \mathrm{m}^{2}$, untuk silt/clay

$\mathrm{N} / 5$ maksimum 10 ton $/ \mathrm{m}^{2}$ untuk sand

SF1 : Safety Factor/Faktor keamanan tahanan ujung $=3$

SF2 : Safety Factor/Faktor keamanan friksi = 3 
Berdasar kekuatan material, daya dukung tiang adalah:

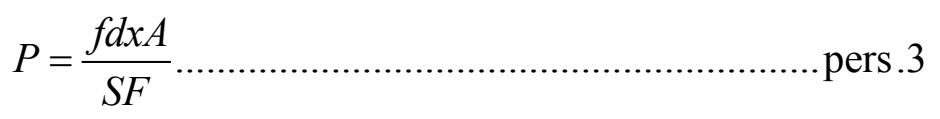

Dimana :

P : Daya dukung ijin tiang $(\mathrm{kN})$

fy : Tegangan leleh pipa baja (MPa)

fd : Tegangan ijin baja $(\mathrm{MPa})=0,6 \times$ fy

t : : Tebal pipa baja $(\mathrm{cm})$

Ap : Luas penampang pipa baja $\left(\mathrm{cm}^{2}\right)=\pi / 4\left(\mathrm{D}^{2}-(\mathrm{D}-2 \times \mathrm{t})^{2}\right)$

SF1 : Safety Factor/Faktor keamanan material $=1,5$

Selain syarat kekuatan, kekakuan atau dalam hal ini penurunan elastik tiang tunggal (S) perlu diperhatikan dengan rumus Vesic (1977):

$\mathrm{S}=\mathrm{S} 1+\mathrm{S} 2+\mathrm{S} 3$ pers. 4

$S=\frac{(Q w p+\xi Q w s) \mathrm{L}}{A p \cdot E p}+\frac{Q w p \cdot C p}{D \cdot q p}+\frac{Q w s \cdot C s}{L \cdot q p} \ldots \ldots \ldots \ldots . . p e r s .5$

Dimana :

S1 : Penurunan batang tiang $(\mathrm{cm})$

Qwp : Beban dipikul ujung tiang $(\mathrm{kN})$

$\xi \quad$ : Koefisien distribusi tahanan kulit sepanjang tiang (0,67 untuk segitiga)

Qws : Beban dipikul selimut tiang $(\mathrm{kN})$

$\mathrm{L} \quad$ : Panjang tiang $(\mathrm{m})$

Ep : Elastisitas tiang (MPa)

S2 : Penurunan akibat beban di ujung tiang $(\mathrm{cm})$

$\mathrm{Cp} \quad$ : Koefisien empiris tanah $(0,04)$

qp : Tahanan ujung batas tiang $\left(\mathrm{kN} / \mathrm{m}^{2}\right)$

S3 : Penurunan akibat beban tersalurkan sepanjang tiang $(\mathrm{cm})$

qs : Tahanan selimut tiang $\left(\mathrm{kN} / \mathrm{m}^{2}\right)$

Cs $\quad$ : Koefisien tanah $=\left(0.93+0.16 \frac{\sqrt{L}}{D}\right) C p$

\section{METODE}

Adapun metodologi penulisan naskah ilmiah berupa studi literatur dan pengambilan data primer dan sekunder sebagai berikut:

1. Mengumpulkan data primer tonase elemen pelengkung dari DED

2. Menentukan Safety Factor (SF) lifting elemen

3. Menentukan kebutuhan alat angkat sesuai beban maksimal yang diangkat, radius dan SF

4. Menentukan SWL, radius dan panjang jib serta boom untuk lifting tiap elemen pelengkung

5. Mengumpulkan data sekunder topografi kondisi eksisting lapangan

6. Menentukan lokasi lifting dan assembly crane

7. Menentukan data sekunder data sheet crane

8. Menentukan material dan dimensi platform crane 
9. Melakukan perhitungan beban yang diterima pondasi platform

10. Mengumpulkan data sekunder hasil SPT

11. Menentukan kelas situs batuan

12. Melakukan analisis pondasi platform dengan menggunakan beban data sheet crane

a. Daya dukung aksial tekan pondasi tiang tunggal dengan Metode Meyerhof (1976)

b. Daya dukung material pondasi tiang tunggal

c. Penurunan pondasi dengan Metode Vesic (1977)

d. Jumlah, jarak dan konfigurasi pondasi tiang

e. Efisensi grup tiang

f. Daya dukung efektif grup tiang

13. Melakukan evaluasi lifting plan dengan peninjauan lapangan

\section{HASIL}

\subsection{Tonase Elemen Pelengkung}

Pemilihan alat angkat harus didasarkan pada berat elemen yang akan diangkut dan radius yang dibutuhkan. Elemen pelengkung jembatan Sei Wampu terdiri dari 15 segmen Top Chord (TC) dan 2 segmen Tie Beam (TB) dengan elemen terberat adalah TC102 yaitu 23,273 ton atau 232,73 kN, berat tiap elemen sebagai berikut pada Gambar 3.1:

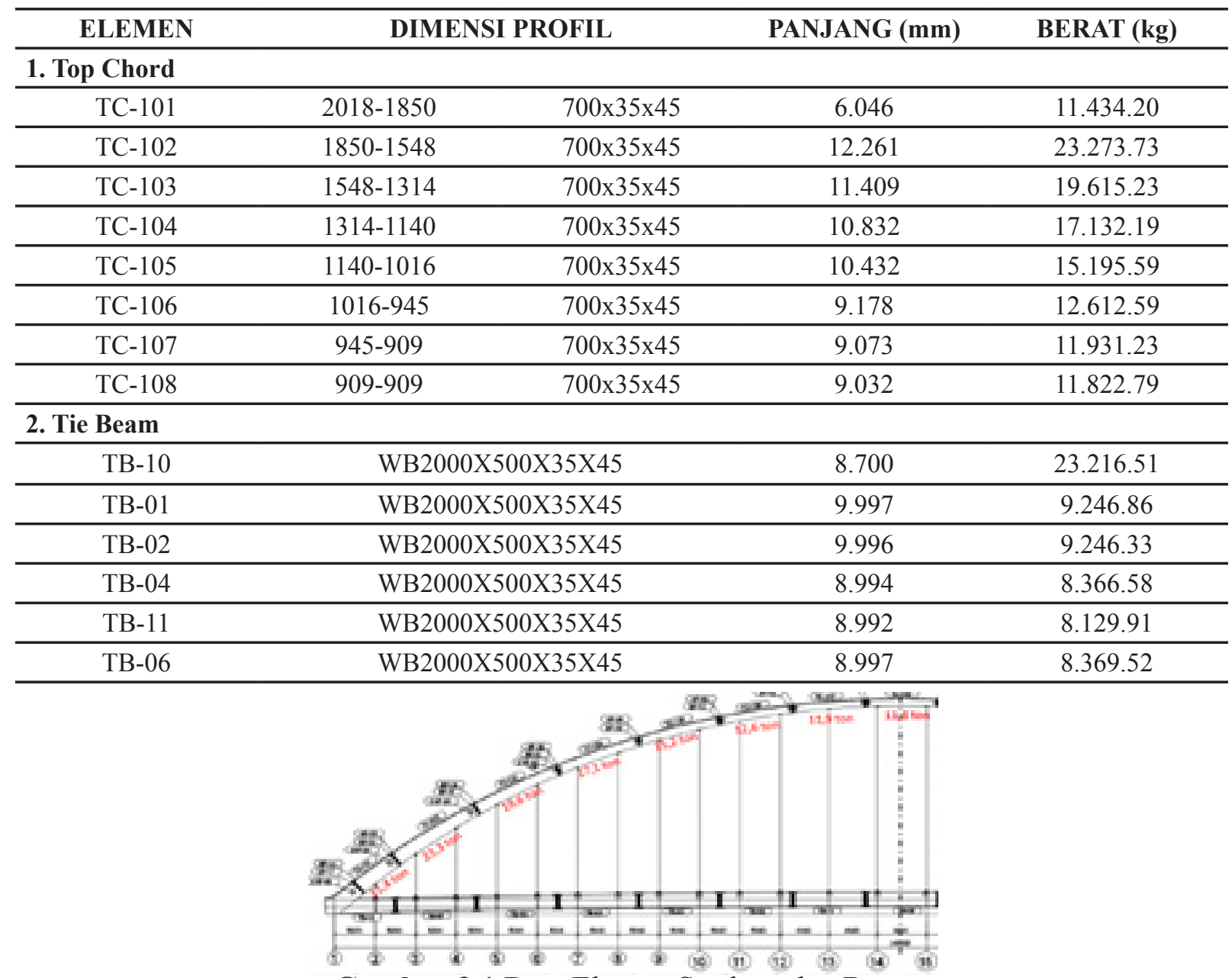

Gambar 3.1 Data Elemen Struktur dan Berat 


\subsection{Kebutuhan Crane dan Lifting Plan}

Dengan SF minimal 2 antara berat elemen dengan SWL Crane dan radius tertentu di lapangan, alat angkat crane 450 ton + Superlift cukup untuk melakukan pengangkatan material TC terberat (TC-102) dari trailer hingga pemasangan terjauh $58 \mathrm{~m}$ (TC-106) di tengah bentang dari sisi Stabat dan $90 \mathrm{~m}$ (TC-107) dari sisi Tj. Pura. Crane 450 ton memiliki radius jangkauan $45 \mathrm{~m}$ - $58 \mathrm{~m}$ dan radius manuver crane 12,5 m. Dengan lokasi yang lebih luas dan lebih sedikit bangunan yang dapat dibebaskan, crane 450 ton dengan superlift 180 ton dapat digunakan pada sisi $\mathrm{Tj}$. Pura untuk memperoleh kapasitas total 600 ton dengan radius jangkauan $50 \mathrm{~m}-86 \mathrm{~m}$ dan manuver yang lebih leluasa dengan radius $19 \mathrm{~m}$. Rencana penggunaan crane dengan boom $60 \mathrm{~m}$ untuk lifting tiap segmen pelengkung ditampilkan sebagai berikut pada Gambar 3.2 dan Tabel 3.1:

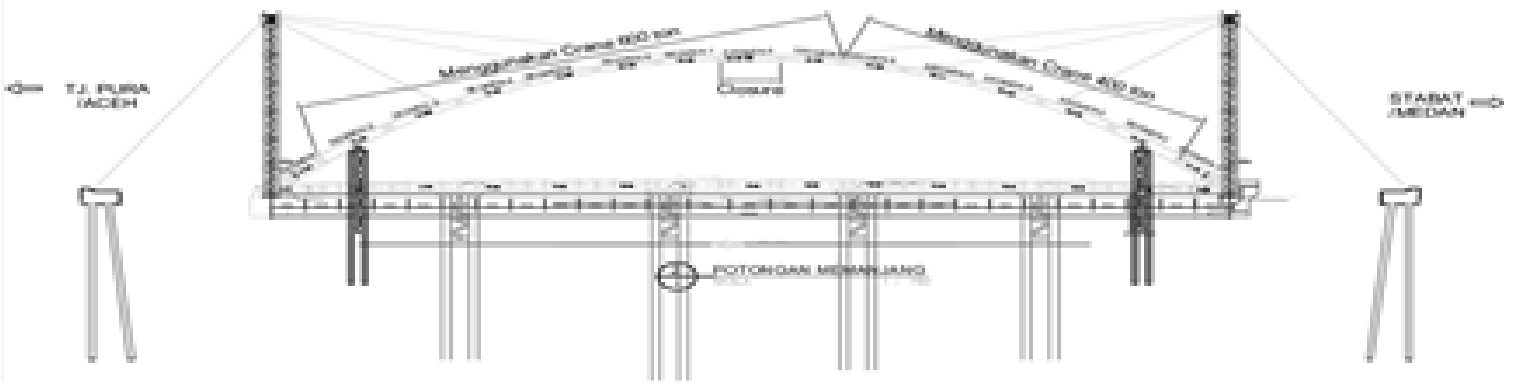

Gambar 3.2 Plotting Penggunaan Crane Sisi Tj. Pura dan Stabat

Tabel 3.1 Rekap Rencana Lifting Elemen Pelengkung

\begin{tabular}{cccccccccc}
\hline No & $\begin{array}{c}\text { Elemen } \\
\text { Pelengkung }\end{array}$ & $\begin{array}{c}\text { Be- } \\
\text { rat } \\
\text { (ton) }\end{array}$ & $\begin{array}{c}\text { Kapasitas } \\
\text { Crane } \\
\text { (ton) }\end{array}$ & $\begin{array}{c}\text { Posisi } \\
\text { Crane }\end{array}$ & $\begin{array}{c}\text { Safe Working } \\
\text { Load/SWL } \\
\text { Crane (ton) }\end{array}$ & $\begin{array}{c}\text { Panjang } \\
\text { Jib (m) }\end{array}$ & $\begin{array}{c}\text { Radius } \\
(\mathbf{m})\end{array}$ & $\begin{array}{c}\text { Sudut } \\
\text { Boom ( }\end{array}$ & SF \\
\hline 1 & TC-101 & 11.4 & 600 & Tj. Pura & 162.3 & 24 & 10 & 86 & 14.24 \\
\hline 2 & TC-102 & 23.3 & 600 & Tj. Pura & 150.8 & 24 & 20 & 86 & 6.47 \\
\hline 3 & TC-103 & 19.6 & 600 & Tj. Pura & 106.4 & 24 & 30 & 86 & 5.43 \\
\hline 4 & TC-104 & 17.1 & 600 & Tj. Pura & 92.3 & 24 & 42 & 76 & 5.40 \\
\hline 5 & TC-105 & 15.2 & 600 & Tj. Pura & 72.9 & 42 & 50 & 76 & 4.80 \\
\hline 6 & TC-106 & 12.6 & 600 & Tj. Pura & 61.4 & 42 & 58 & 76 & 4.87 \\
\hline 7 & TC-107 & 11.9 & 600 & Tj. Pura & 47.4 & 54 & 70 & 76 & 3.98 \\
\hline 8 & TC-108 & 11.8 & 600 & Tj. Pura & 39.2 & 66 & 78 & 76 & 3.32 \\
\hline 9 & TC-107 & 11.9 & 600 & Tj. Pura & 27.6 & 66 & 90 & 66 & 2.32 \\
\hline 10 & TC-106 & 12.6 & 450 & Stabat & 25.6 & 54 & 58 & 86 & 2.03 \\
\hline 11 & TC-105 & 15.2 & 450 & Stabat & 34.8 & 54 & 50 & 86 & 2.29 \\
\hline 12 & TC-104 & 17.1 & 450 & Stabat & 38.4 & 24 & 42 & 86 & 2.25 \\
\hline 13 & TC-103 & 19.6 & 450 & Stabat & 72.5 & 24 & 30 & 86 & 3.70 \\
\hline 14 & TC-102 & 23.3 & 450 & Stabat & 108.7 & 24 & 20 & 86 & 4.67 \\
\hline 15 & TC-101 & 11.4 & 450 & Stabat & 121.3 & 24 & 10 & 86 & 10.64 \\
\hline
\end{tabular}

Lokasi crane menyesuaikan kondisi eksisting di lapangan dimana terdapat rumah warga pada sisi Stabat dan gudang tidak terpakai pada sisi Tj. Pura sehingga crane dengan kapasitas lebih besar dapat digunakan di sisi Tj. Pura. Lifting plan dapat dilihat pada Gambar 3.3 sebagai berikut: 


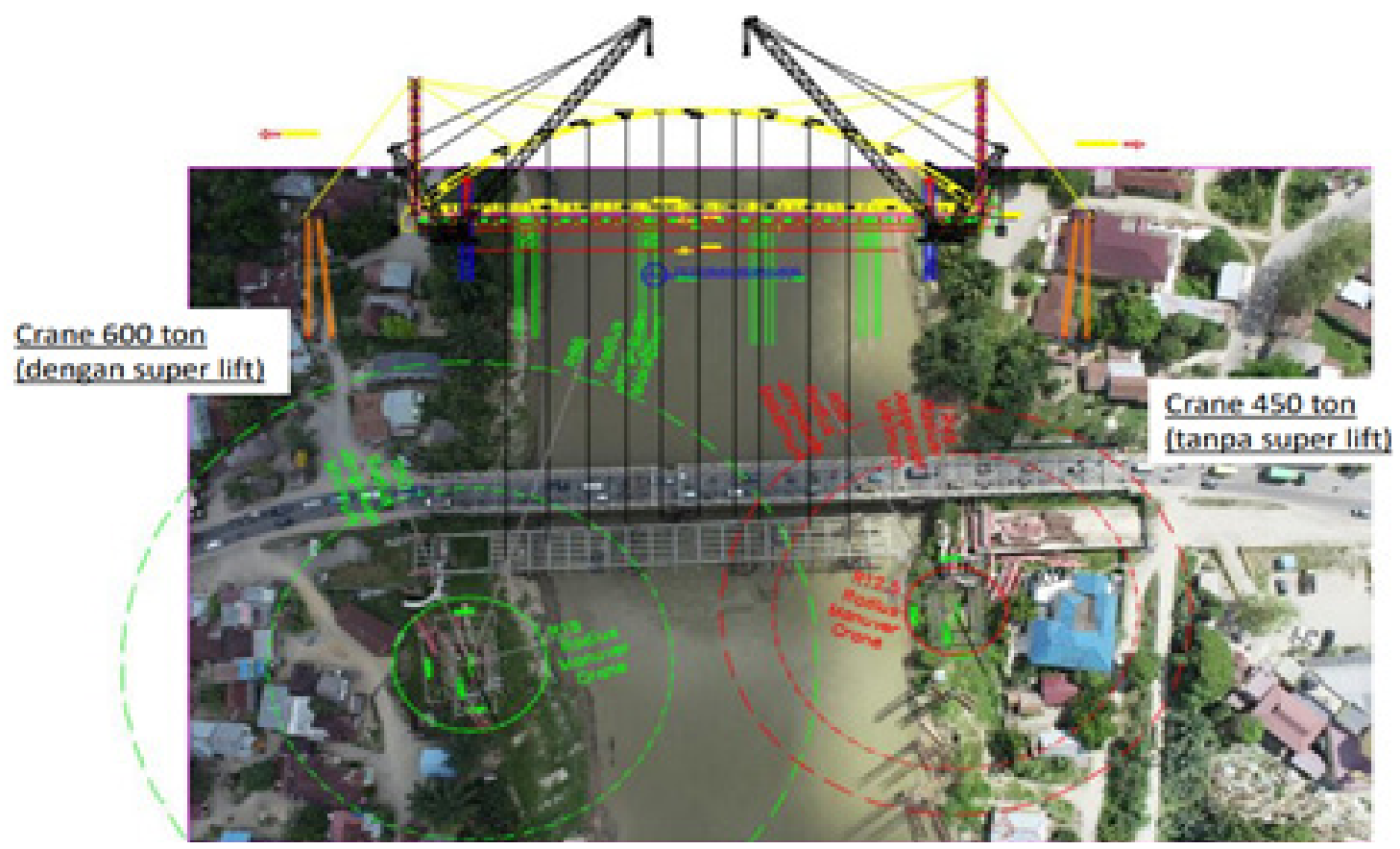

Gambar 3.3 Lifting Plan Crane Sisi Tj. Pura dan Stabat

\subsection{Platform}

Untukmemastikan pijakan yangmemenuhiaspek kekuatan dankekakuanagartidak terjadipenurunan diferensial yang berpotensi berbahaya crane terguling saat lifting, platform beton diperlukan untuk menjadi lantaikerja heavy crane. Dengan data darivendor, berat crane tipe TEREX 600 T pada Tabel 3.2 sebagai berikut:

\begin{tabular}{clc}
\multicolumn{1}{c}{ Tabel } & 3.2 Data Berat Crane TEREX $600 \mathrm{~T}$ \\
\hline No & \multicolumn{1}{c}{ Item } & Berat (ton) \\
\hline 1 & Body & 64 \\
\hline 2 & Trek Kiri & 40 \\
\hline 3 & Trek Kanan & 40 \\
\hline 4 & Max Counterweight & 180 \\
\hline 5 & Counterweight & 30 \\
\hline 6 & Boom Foot & 30 \\
\hline 7 & Boom Sec $12 \mathrm{~m}$ & 7 \\
\hline 8 & Boom Sec $6 \mathrm{~m}$ & 4 \\
\hline 9 & Boom Sec $12 \mathrm{~m}$ & 7 \\
\hline 10 & Boom Sec $12 \mathrm{~m}$ & 7 \\
\hline 11 & Boom Sec $12 \mathrm{~m}$ & 7 \\
\hline 12 & Top Boom & 5.2 \\
\hline 13 & SL Mast Boom & 30 \\
\hline 14 & SL Counterweight & 150 \\
\hline 15 & Hook Block 110 ton & 2 \\
\hline 16 & Lifting Jib $66 \mathrm{~m}$ & 30 \\
\hline 17 & Asesori & 20 \\
\hline Total & 653.2 \\
\hline
\end{tabular}


Menyesuaikan dimensi dan kebutuhan minimal manuver crane, luas platform ditentukan $15 \mathrm{~m}$ x $15 \mathrm{~m}$. Karena pembobokan plat beton akan sulit dilakukan saat pekerjaan lifting selesai, maka plat baja dengan tebal $5 \mathrm{~cm}$ digunakan untuk distribusi merata antar pondasi tiang. Berat total yang harus ditahan pondasi berupa berat sendiri plat baja, crane beserta asesorisnya dan segmen terberat yang akan diangkat sebagai berikut pada Tabel 3.3:

\begin{tabular}{lll}
\hline \multicolumn{1}{c}{ Parameter } & \multicolumn{1}{c}{ Nilai } & Satuan \\
\hline Lebar $(\mathrm{b})$ & 15 & $\mathrm{~m}$ \\
\hline Panjang $(\mathrm{h})$ & 15 & $\mathrm{~m}$ \\
\hline Luas Plat $(\mathrm{A})$ & 225 & $\mathrm{~m}^{2}$ \\
\hline Tebal Plat $(\mathrm{t})$ & 0.05 & $\mathrm{~m}$ \\
\hline Volume Plat $(\mathrm{V})$ & 11.25 & $\mathrm{~m}^{3}$ \\
\hline BJ baja & 78.5 & $\mathrm{kN} / \mathrm{m}^{3}$ \\
\hline BJ beton & 25 & $\mathrm{kN} / \mathrm{m}^{3}$ \\
\hline $\mathrm{g}$ & 10 & $\mathrm{~m} / \mathrm{s}^{2}$ \\
\hline Berat plat & 883.125 & $\mathrm{kN}$ \\
\hline Berat crane & 6532 & $\mathrm{kN}$ \\
\hline Berat segmen & 232.73 & $\mathrm{kN}$ \\
\hline Berat Total & 7647.855 & $\mathrm{kN}$ \\
\hline
\end{tabular}

Data tanah yang digunakan untuk desain adalah yang lebih konservatif yaitu pada borehole 1 (BH 01) di sisi Stabat dengan jenis tanah didominasi lempung, rata-rata nilai N-SPT 14,07 untuk 30 m lapisan teratas dan kondisi kelas situs batuan tanah lunak (SE) sebagai berikut pada Tabel 3.4:

Tabel 3.4 Hasil SPT Tanah pada BH 01

\begin{tabular}{|c|c|c|c|c|c|c|c|c|}
\hline \multirow{2}{*}{$\begin{array}{l}\text { Depth } \\
\text { (mi) }\end{array}$} & \multirow[t]{2}{*}{ Type of Soil } & \multirow[t]{2}{*}{ N-SPT } & \multicolumn{4}{|c|}{ Grafik SPT } & \multirow[t]{2}{*}{ ti } & \multirow[t]{2}{*}{$\mathrm{t} / \mathrm{N}$} \\
\hline & & & \multirow{7}{*}{$\begin{array}{r}+60 \\
+100 \\
.+000\end{array}$} & \multicolumn{3}{|c|}{$0 \quad 20 \quad 40 \quad 60 \quad 80$} & & \\
\hline 0.00 & Fa Msterial & 0 & & & \multirow{2}{*}{1} & 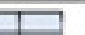 & \multirow[b]{2}{*}{2} & \multirow[b]{2}{*}{0.133} \\
\hline 2.00 & \multirow{2}{*}{ Sandy clay, very stif, trown. } & 15 & & & & 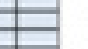 & & \\
\hline 400 & & 3 & & & 튼 & 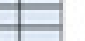 & 2 & 0.667 \\
\hline 600 & \multirow{3}{*}{$\begin{array}{l}\text { Sify clay, wot to medium stif } \\
\text { Sand, medum dense to } \\
\text { derne, black. }\end{array}$} & 5 & & & E & $\square$ & 2 & 0.400 \\
\hline-900 & & 21 & & & E- & $\square$ & 2 & 0.005 \\
\hline .1000 & & 44 & & & $\triangle$ & $\square$ & 2 & 0045 \\
\hline .1200 & Sand medium dense to dense & 39 & & & $=$ & $\square$ & 2 & 0061 \\
\hline .1400 & & 16 & -1200 & & 7 & $\square$ & 2 & 0.128 \\
\hline-16.00 & 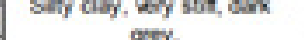 & 19 & .1400 & & 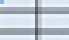 & 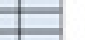 & 2 & 0.105 \\
\hline-1600 & & 10 & .1600 & & 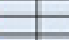 & + & 2 & 0,200 \\
\hline 2000 & Come sungy cloy, with & 16 & .1800 & & - & 1 & 2 & 0.111 \\
\hline 2200 & monic, stif dark gry. & 12 & .2000 & & E & $\square$ & 2 & 0.967 \\
\hline .24 .00 & Satty clay, wit, browrish & 14 & .2200 & & 픈 & $\square$ & 2 & 0.143 \\
\hline .2600 & gey. & 53 & .2400 & & E & 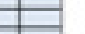 & 2 & 00038 \\
\hline .28 .00 & Sandy se hard grey. & 57 & & & $y$ & + & 2 & 0.035 \\
\hline .30 .00 & & 60 & 2600 & & $\theta$ & \# & 2 & 0.033 \\
\hline 31.00 & & 60 & -2800 & & + & 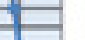 & 1 & 0.017 \\
\hline$\$ 200$ & $\begin{array}{l}\text { Gratly cosine sand, woy } \\
\text { dense. black. }\end{array}$ & 60 & .3000 & & - & 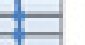 & 1 & 0,017 \\
\hline-300 & & 60 & -1200 & & 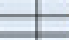 & $t$ & 1 & 0017 \\
\hline 300 & & 60 & -1400 & & 1 & 7 & 1 & 0,017 \\
\hline & & & & & 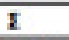 & & 34 & 2416 \\
\hline & & & & Nrat: & ta-rata & & & \\
\hline & & & & Kolas & is situ & & & \\
\hline
\end{tabular}


42 JURNAL BANGUNAN, VOL. 26, NO.2, OKTOBER 2021: 33-46

Karena platform terletak di bantaran sungai dengan data tanah relatif lunak, tanah keras terletak pada kedalaman $26 \mathrm{~m}$ serta alat boredpile sulit dimobilisasi, digunakan pondasi dalam tiang pancang baja agar dapat memberi sambungan yang kuat dengan plat baja platform dengan pengelasan. Diameter tiang baja ditentukan $600 \mathrm{~mm}$ dengan tebal $12 \mathrm{~mm}$ dan panjang $15 \mathrm{~m}$. Untuk memastikan pondasi kuat menahan beban yang bekerja, daya dukung tiang berdasar kekuatan material dan hasil uji tanah SPT perlu dihitung. Hasil perhitungan daya dukung aksial tekan pondasi tiang berdasar material dengan SF 1,5 pada Tabel 3.5 dan daya dukung tanah dengan efisiensi grup tiang (Eg) pada Tabel 3.6 dan Gambar 3.4 sebagai berikut:

Tabel 3.5 Daya Dukung Aksial Pondasi Tiang berdasar Material

\begin{tabular}{lll}
\hline \multicolumn{1}{c}{ Parameter } & \multicolumn{1}{c}{ Nilai } & Satuan \\
\hline Kuat Leleh (fy) & 245 & $\mathrm{MPa}$ \\
\hline Tegangan Izin Baja (0.6 fy) & 147 & $\mathrm{MPa}$ \\
\hline Diameter (D) & 0.6 & $\mathrm{~m}$ \\
\hline Tebal (t) & 12 & $\mathrm{~mm}$ \\
\hline Luas Pancang Baja (A) & 0.022 & $\mathrm{~m} 2$ \\
\hline Safety Factor (SF) & 1.5 & \\
\hline Daya Dukung Material & $\mathbf{2 1 7 2 . 3 7 4}$ & $\mathbf{k N}$ \\
\hline
\end{tabular}

Tabel 3.6 Daya Dukung Aksial Tekan Pondasi Tiang berdasar SPT

\begin{tabular}{|c|c|c|c|c|c|c|c|c|c|}
\hline $\begin{array}{c}\text { fi=PANJANG } \\
\text { TIANG (m) }\end{array}$ & $\begin{array}{c}\text { KEND- } \\
\text { ALAMA } \\
\text { N (m) }\end{array}$ & N-SPT & $\begin{array}{c}\text { DESKRIP- } \\
\text { SI } \\
\text { LAPISAN }\end{array}$ & fi $\left(\operatorname{ton} / \mathbf{m}^{2}\right)$ & fi $\left(\operatorname{ton} / \mathbf{m}^{2}\right)$ & $\begin{array}{c}\mathrm{Ps}=(\mathbf{f} * \mathbf{A s} / \\
\mathrm{SF}) * \mathrm{Eg} \\
(\mathbf{t o n} / \mathbf{m})\end{array}$ & $\begin{array}{c}\text { Ps 1 } \\
\text { tiang=li(fi*As/ } \\
\text { SF)*Eg (ton) }\end{array}$ & $\begin{array}{c}\mathbf{P b} 1 \\
\text { tiang= } \\
{ }^{*} \mathbf{N}^{*} \mathbf{A b} / \\
\mathbf{S F})^{*} \mathbf{E g} \\
\text { (ton) }\end{array}$ & $\begin{array}{c}\text { Pijin 1 } \\
\text { tiang (ton) }\end{array}$ \\
\hline 0.00 & 0.00 & 0 & $\begin{array}{c}\text { FILL } \\
\text { MATE- } \\
\text { RIAL }\end{array}$ & & & & & & \\
\hline 2.00 & 2.00 & 15 & $\begin{array}{l}\text { LEM- } \\
\text { PUNG }\end{array}$ & 0.00 & 0.00 & 0.00 & 0.00 & 28.87 & 28.87 \\
\hline 4.00 & 4.00 & 3 & $\begin{array}{l}\text { LEM- } \\
\text { PUNG }\end{array}$ & 3.00 & 1.50 & 0.86 & 3.42 & 15.40 & 18.82 \\
\hline 6.00 & 6.00 & 5 & $\begin{array}{l}\text { LEM- } \\
\text { PUNG }\end{array}$ & 5.00 & 2.67 & 1.52 & 9.13 & 11.55 & 20.68 \\
\hline 8.00 & 8.00 & 21 & PASIR & 4.20 & 3.05 & 1.74 & 13.92 & 43.63 & 57.55 \\
\hline 10.00 & 10.00 & 44 & PASIR & 8.80 & 4.20 & 2.40 & 23.96 & 98.17 & 122.13 \\
\hline 12.00 & 12.00 & 39 & PASIR & 7.80 & 4.80 & 2.74 & 32.85 & 103.31 & 136.16 \\
\hline 14.00 & 14.00 & 16 & $\begin{array}{l}\text { LEM- } \\
\text { PUNG }\end{array}$ & 12.00 & 5.83 & 3.32 & 46.54 & 55.82 & 102.37 \\
\hline 16.00 & 16.00 & 19 & $\begin{array}{l}\text { LEM- } \\
\text { PUNG }\end{array}$ & 12.00 & 6.60 & 3.76 & 60.23 & 46.84 & 107.07 \\
\hline
\end{tabular}




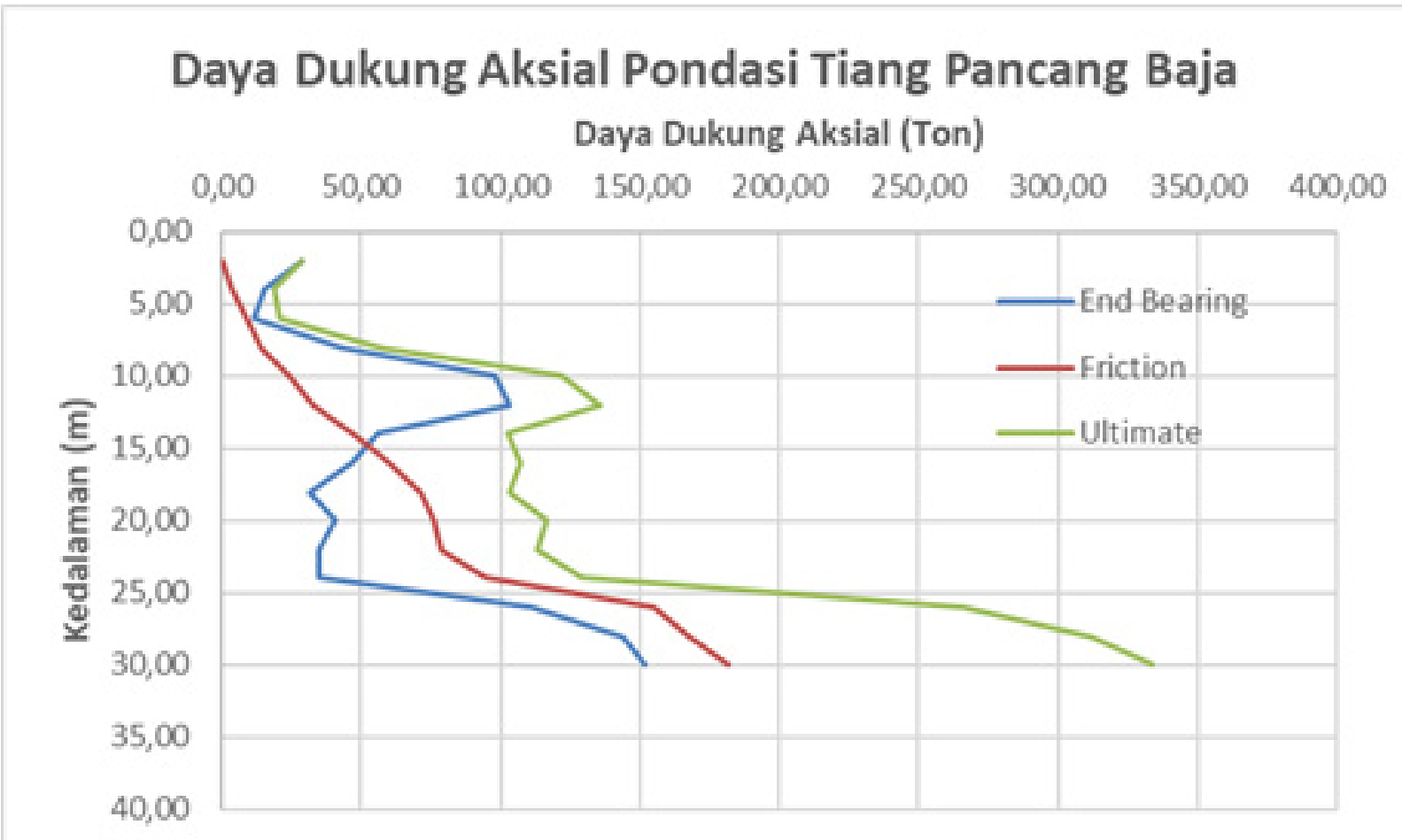

Gambar 3.4 Daya Dukung Aksial Pondasi

Dari daya dukung tiang berdasar material dan tanah, diambil yang terkecil yaitu daya dukung tanah karena lebih menentukan. Deformasi vertikal atau penurunan tiang diperoleh $<$ batas ijin $1 \mathrm{~cm}$ sesuai Tabel 3.7 berikut:

Tabel 3.7 Penurunan Elastik Tiang

\begin{tabular}{lcc}
\hline \multicolumn{1}{c}{ Parameter } & Nilai & Satuan \\
\hline Beban Ujung (Qwp) & 55.26 & ton \\
\hline Koefisien distribusi ( ) & 0.67 & ton \\
\hline Beban selimut (Qws) & 49.36 & ton $/ \mathrm{m} 2$ \\
\hline Elastisitas tiang (Ep) & 20.000 .000 & $\mathrm{~cm}$ \\
\hline Penurunan batang tiang (S1) & 0.023 & \\
\hline Koefisien tanah (Cp) & 0.04 & ton $/ \mathrm{m} 2$ \\
\hline Tahanan ujung tiang (S2) & 525 & $\mathrm{~cm}$ \\
\hline Penurunan ujung tiang (S2) & 0.702 & \\
\hline Koefisien tanah (Cs) & 0.069 & $\mathrm{~cm}$ \\
\hline Penurunan sepanjang tiang (S3) & 0.043 & $\mathbf{c m}$ \\
\hline \multicolumn{1}{c}{ penurunan Total (S) } & $\mathbf{0 . 7 6 8}$ & \\
\hline
\end{tabular}

Dengan memperhitungkan efisiensi jarak pada grup tiang pada analisis sebelumnya, diperoleh jumlah tiang 9 dan konfigurasi tiang 3 x 3 sebagai berikut pada Tabel 3.8 dan Gambar 3.5: 
44 JURNAL BANGUNAN, VOL. 26, NO.2, OKTOBER 2021: 33-46

Tabel 3.8 Kebutuhan Tiang Pancang

\begin{tabular}{lcc}
\hline \multicolumn{1}{c}{ Parameter } & Nilai & Satuan \\
\hline Baris $(\mathrm{m})$ & 3 & \\
\hline Kolom $(\mathrm{n})$ & 3 & \\
\hline 0 & 6.23 & $\mathrm{~m}$ \\
\hline Jarak Tiang $(\mathrm{S})$ & 5.5 & \\
\hline Eff & 0.91 & $\mathrm{kN}$ \\
\hline Qu tiang & 1070.72 & tiang \\
\hline Jumlah & 7.14 & tiang \\
\hline
\end{tabular}

Gambar 3.5 Konfigurasi Tiang Pancang Baja 3 x 3 pada Platform 15 m x 15 m

\section{PEMBAHASAN}

Dari hasil analisis, pembahasan sebagai berikut:

a. Elemen pelengkung terberat yang akan diangkat adalah $\mathrm{TC}-102$ (23,3 ton) dan ra dius terjauh adalah $58 \mathrm{~m}$ untuk Crane 450 ton dan $90 \mathrm{~m}$ untuk Crane 600 ton

b. Belum ada aturan tertulis SF lifting $=2$, namun pemilihan SF didasarkan atas ben tang utama Sei Wampu yang merupakan jembatan khusus karena pelengkung den gan bentang > $60 \mathrm{~m}$ memerlukan persetujuan KKJTJ dan K2K sesuai Permen 41/2015

c. Crane 450 ton yang dipergunakan berjumlah 1 untuk optimasi biaya penye waan crane sehingga hanya diperlukan 1 kali biaya mobilisasi dan demobilisasi

d. Pemilihan heavy crane 450 ton + superlift 180 ton telah menyesuaikan kondi si eksisting dengan radius manuver crane $19 \mathrm{~m}$ dan kapasitas kebutuhan 600 ton tanpa menambah dimensi crane yang akan menyulitkan jalan akses ke lokasi lifting

e. Pondasi platform didesain menggunakan tahanan friksi/floating pile pada ke 
dalaman $15 \mathrm{~m}$ karena merupakan temporary structure dan daya dukung ak sial telah dihitung menggunakan SF 3 sesuai persyaratan struktur permanen f. Pondasi platform pada tiap sisi menggunakan 9 tiang pancang baja $\varnothing \quad 60 \mathrm{~cm}$ kedalaman $15 \mathrm{~m}$ dengan daya dukung tiang tunggal leb

ih ditentukan berdasar SPT (107 ton) dibanding kekuatan material (217 ton) g. Penurunan elastik tiang $0,768 \mathrm{~cm}<1 \mathrm{~cm}$ sesuai persyaratan

\section{SIMPULAN}

Untuk melakukan lifting bentang utama Jembatan Sei Wampu sesuai kondisi lapangan, Heavy crane 450 ton dapat digunakan untuk melakukan lifting 6 segmen di arah Stabat dan heavy crane 450 ton + superlift 180 ton untuk lifting 9 segmen arah Tj. Pura dengan menggunakan platform plat baja $15 \mathrm{~m}$ x $15 \mathrm{~m}$ dan jumlah pondasi 9 tiang pancang baja $\varnothing 60 \mathrm{~cm}$ dan kedalaman $15 \mathrm{~m}$.

Saran yang dapat diberikan untuk analisis lebih lanjut : a. Sebelum lifting dimulai, perlu dilakukan loading test crane menggunakan segmen terberat agar memastikan immediate settlement terjadi, b. Hanya terdapat beberapa vendor lokal yang menyediakan Crane 450 ton untuk disewa, sehingga pengecekan terhadap kondisi penyedia crane sangat diperlukan, c. Pembiayaan perlu memperhitungkan Service crane 150 ton karena dibutuhkan untuk assembly crane, pemasangan superlift dan erection tower backstay yang tidak dianalisis pada penelitian berikut

\section{DAFTAR RUJUKAN}

Chen, W. F. \& Duan L. 2003. Bridge Engineering Construction and Maintenance. CRC Press. Amerika.

Dewantoro, B. S. \& Mardiyanto, A. 2019. Manajemen Resiko Kerja pada Studi Kasus Jem batan Kali Kuto. Fakultas Teknik Jurusan Teknik Sipil Universitas Semarang. Semarang. EXECUTIVE SUMMARY JEMBATAN KALIKUTO PROYEK JALAN TOL BATANG SEMARANG SEKSI 2. 2018. Jasamarga Semarang - Batang. Semarang.

Ismerianto, Nuh, S. M. \& Syahrudin. METODE PELAKSANAAN STRUKTUR ATAS JEM BATAN TAYAN. Program Studi Teknik Sipil Universitas Tanjungpura Pontianak. Ponti anak.

Izza, F. K., Praditama, M. A., Kirana, C. N., Setiyono, K. J. \& Sudarmono. 2019. KAJIAN WAKTU PENYELESAIAN METODE CRANE DAN METODE LAUNCHER DALAM PELAKSANAAN ERECTION GIRDER JEMBATAN (Studi Kasus : Pembangunan Jalan Tol Semarang - Solo Ruas Salatiga - Boyolali Sta 40+409 - Sta 71+785). Wahana TEKNIK SIPIL Vol. 24 No. 1 Juni 2019. Semarang.

Lifting Charts - Rough Terrain Cranes: TADANO MODEL TR-500XL-3- 50 TON CAPACITY Manual Pemeliharaan Jembatan Pelengkung Baja. 2011. Kementerian Pekerjaan Umum dan Perumahan Rakyat. Jakarta. 
46 JURNAL BANGUNAN, VOL. 26, NO.2, OKTOBER 2021: 33-46

Nurdin, F.. Habir, Syaputra, Z, 2016. PERBANDINGAN TIANG PANCANG BAJA DAN BETON PADA PERENCANAAN DINDING PENAHAN TANAH CANTILEVER DI KM09 JALAN POROS SAMARINDA - TENGGARONG DITINJAU DARI SEGI BIAYA DAN KEAMANAN. Universitas 17 Agustus 1945 Samarinda.

Prasmoro, R., Masiran, H. S. \& Wahyuni, E. 2017. Modifikasi Jembatan Sembayat Baru II Menggunakan Sistem Jembatan Busur Rangka Baja. Jurnal Teknik ITS Vol. 6, No. 1. Sura baya.

SAFE BOLTED JOINT DESIGN: AN INTRODUCTION TO WHY BOLTED JOINTS FAIL AND HOW TO MAKE THEM SAFER. 2021. Nord-Lock Group. Singapura. Septiawan, H. G. \& Irawan, D. 2013. DESAIN JEMBATAN BARU PENGGANTI JEM BATAN KUTAI KARTANEGARA DENGAN SISTEM BUSUR. JURNAL TEKNIK PO MITS Vol. 1, No. 1. Surabaya.

Utama, S. F., Patty, A. H. \& Naibaho, A. PERBANDINGAN ERECTION RANGKA BAJA JEMBATAN DENGAN MENGGUNAKAN MAST CRANE DAN TOWER CRANE PADA PROYEK JEMBATAN TRISULA BLITAR. Jurnal PROKONS Politeknik Negeri Malang. Malang. 